\title{
In-Source Fragmentation Technique for the Production of Thermalized Ions
}

\author{
Damon R. Carl, Robert M. Moision, and P. B. Armentrout \\ Department of Chemistry, University of Utah, Salt Lake City, Utah, USA
}

Our electrospray ionization-ion funnel-rf hexapole (ESI-IF-6P) source is designed to produce ions for threshold collision-induced dissociation (TCID) studies in a guided ion beam mass spectrometer. This ion source forms an initial distribution of $\mathrm{Ca}^{2+}\left(\mathrm{H}_{2} \mathrm{O}\right)_{x}$ ions where $x$ is 6-9. A new in-source fragmentation technique within the hexapole ion guide of the source is described, which is easy to implement and of modest machining and electrical costs, and is able to generate smaller $\mathrm{Ca}^{2+}\left(\mathrm{H}_{2} \mathrm{O}\right)_{x}$ complexes, where $x=2-5$. Fragmentation is achieved by biasing an assembly of six $0.25 \mathrm{in}$. long electrodes that are inserted between the hexapole rods. The assembly is positioned in the high-pressure region of the source such that newly formed $\mathrm{Ca}^{2+}\left(\mathrm{H}_{2} \mathrm{O}\right)_{x}$ ions undergo enough collisions to become thermalized, as verified by TCID studies. From the initial distribution of ions, fragmentation proceeds along the lowest energy pathway, which corresponds to sequential water loss for most complexes. However, the $\mathrm{Ca}^{2+}\left(\mathrm{H}_{2} \mathrm{O}\right)$ complex cannot be formed using this method because charge separation into $\mathrm{CaOH}^{+}$and $\mathrm{H}_{3} \mathrm{O}^{+}$becomes the lowest energy pathway from the $\mathrm{Ca}^{2+}\left(\mathrm{H}_{2} \mathrm{O}\right)_{2}$ complex. Therefore, this fragmentation technique can be used to identify the critical size complex for $\mathrm{M}^{2+}\left(\mathrm{H}_{2} \mathrm{O}\right)_{x}$ systems, which we define as the complex size $(x)$ at which charge separation becomes a lower energy pathway compared with simple ligand loss. (J Am Soc Mass Spectrom 2009, 20, 2312-2317) (c) 2009 American Society for Mass Spectrometry

I n-source fragmentation techniques are pervasive within the field of proteomics for top-down sequencing that provides structural information. Cone-skimmer and nozzle-skimmer dissociation are well-known fragmentation techniques that accelerate ions between static lenses in the high-pressure region of a mass spectrometer, thereby providing additional internal energy into ion complexes to induce dissociation $[1,2]$. Consecutive steps of nozzle-skimmer activation [3] in an electrospray ionization Fourier transform ion cyclotron resonance mass spectrometer (ESI-FTICR) have been shown to increase the number of backbone fragmentation pairs of $8^{+}-11^{+}$ubiquitin ions compared with activation in the FTICR cell by sustained offresonance irradiation collision-activated dissociation (SORI-CAD) [4] and infrared multiphoton dissociation (IRMPD) [5].

Fragmentation can also take place in accumulation radio frequency (rf) multipole ion guides external to the analysis region of the mass spectrometer. Fragmentation techniques include multipole-storage-assisted dissociation (MSAD) [6], ion "threshing" [7], and external infrared multiple photon dissociation (IRMPD) [8]. MSAD involves trapping ions within a hexapole by creating an axial well using a hexapole offset voltage with respect to entrance and exit cap plates. The degree

Address reprint requests to Professor P. B. Armentrout, Department of Chemistry, University of Utah, 315 S. 1400 E., Room 2020, Salt Lake City, UT 84112, USA. E-mail: armentrout@chem.utah.edu of fragmentation depends on the depth of the axial well and the amount of time the ions spend in the trap [9]. Ion "threshing" utilizes an axial potential gradient within an octopole ion guide by placing tilted wires between octopole rods. Switching the wires between positive and negative DC voltages multiple times over a millisecond timescale induces energetic ion-neutral collisions and leads to fragmentation. The extent of fragmentation depends on the frequency, amplitude, and number of field reversals of the applied static potential [7]. Fragmentation can also be induced via dipolar resonant excitation by supplying a small supplementary dipolar rf voltage at the secular frequency of the ion of interest to a pair of opposite rods in a quadrupole ion guide that acts as a mass filtering linear ion trap $[10,11]$. In combination with dipolar excitation, the efficiency of fragmentation has been shown to increase within the linear ion trap by placing DC-only auxiliary electrodes between the quadrupole rods, which creates higher order fields within the trap [12]. In this implementation, the electrodes span the entire length of the quadrupole. Extensive fragmentation can also occur with broadband resonant excitation waveforms in quadrupole ion guides before an ICR cell [13]. Even though the current techniques for fragmentation have been predominantly investigated for large macromolecules, they can also be utilized for much smaller ion complexes.

In this paper, we describe the implementation of a new in-source fragmentation technique that utilizes 
additional DC electrodes between the hexapole ion guide rods in our ESI-ion funnel-rf hexapole (ESI-IF-6P) source [14]. We illustrate our approach by applying it to $\mathrm{Ca}^{2+}\left(\mathrm{H}_{2} \mathrm{O}\right)_{x}$ complexes [15]. Here, $x=2-5$ complexes are formed from an initial distribution where $x$ is always $\geq 6$. The $\mathrm{Ca}^{2+}\left(\mathrm{H}_{2} \mathrm{O}\right)_{x}$ complexes formed in this way are subjected to threshold collision-induced dissociation (TCID) in a guided ion beam tandem mass spectrometer (GIBMS). These studies indicate that the reactant ions are thermalized, but only when the electrodes are located in the high-pressure region of the hexapole ion guide and only when modest electrode voltages are utilized.

\section{Experimental}

\section{In-Source Fragmentation}

The ESI-IF-6P source, shown in Figure 1, produces an initial distribution of $\mathrm{Ca}^{2+}\left(\mathrm{H}_{2} \mathrm{O}\right)_{x}$ complexes, where $x$ is always 6-9. Fragmentation of larger $\mathrm{Ca}^{2+}\left(\mathrm{H}_{2} \mathrm{O}\right)_{x}$ complexes to form the smaller $\mathrm{Ca}^{2+}\left(\mathrm{H}_{2} \mathrm{O}\right)_{x}$ ions is achieved by placing six $0.25 \mathrm{in.}$ long brass electrodes (0.032 in. thickness) between the $6.0 \mathrm{in}$. long hexapole rods. The electrodes or "fins", as we have termed them, each get the same DC bias. For most of the work described here, the fins are located at position 2 in Figure 1, in the high-pressure region of the source chamber, $\mathrm{P}_{\mathrm{SRC}} \approx$ $10^{-2}$ Torr, $\sim 3.5 \mathrm{in}$. from the entrance to the hexapole ion guide and before the conductance limiting aperture separating the two pumping regions spanned by the hexapole ion guide. Positioning the fins further upstream in the high-pressure region of the hexapole (position 1) as well as downstream in the second pumping region of the hexapole (position 3) was also tested, as discussed further below. A custom assembly holds the fins in place, insuring that they remain electrically isolated from the hexapole rods. The inner edges of the electrodes are located $0.140 \mathrm{in}$. from the central axis of the hexapole and are designed such that they do not extend into the trapping volume of the hexapole ion guide.

\section{TCID Studies}

Cross sections for the CID of the $\mathrm{Ca}^{2+}\left(\mathrm{H}_{2} \mathrm{O}\right)_{x}$ complexes are measured using a GIBMS that has been previously described in detail $[16,17]$. The $\mathrm{Ca}^{2+}\left(\mathrm{H}_{2} \mathrm{O}\right)_{x}$ complexes are produced with an ESI source [14]. Ions are extracted from the source and mass-selected using a magnetic momentum analyzer. Reactant ions are then decelerated to well-defined kinetic energies and focused into a rf octopole ion guide, trapping the ions radially [18]. The octopole minimizes reactant and product ion losses resulting from scattering. The octopole is surrounded by a static gas cell containing Xenon gas at a pressure of $\sim 0.08$ mTorr. After collision, unreacted parent and product ions drift to the end of the octopole, where they are mass-selected using a quadrupole mass filter and detected using a scintillation ion detector capable of

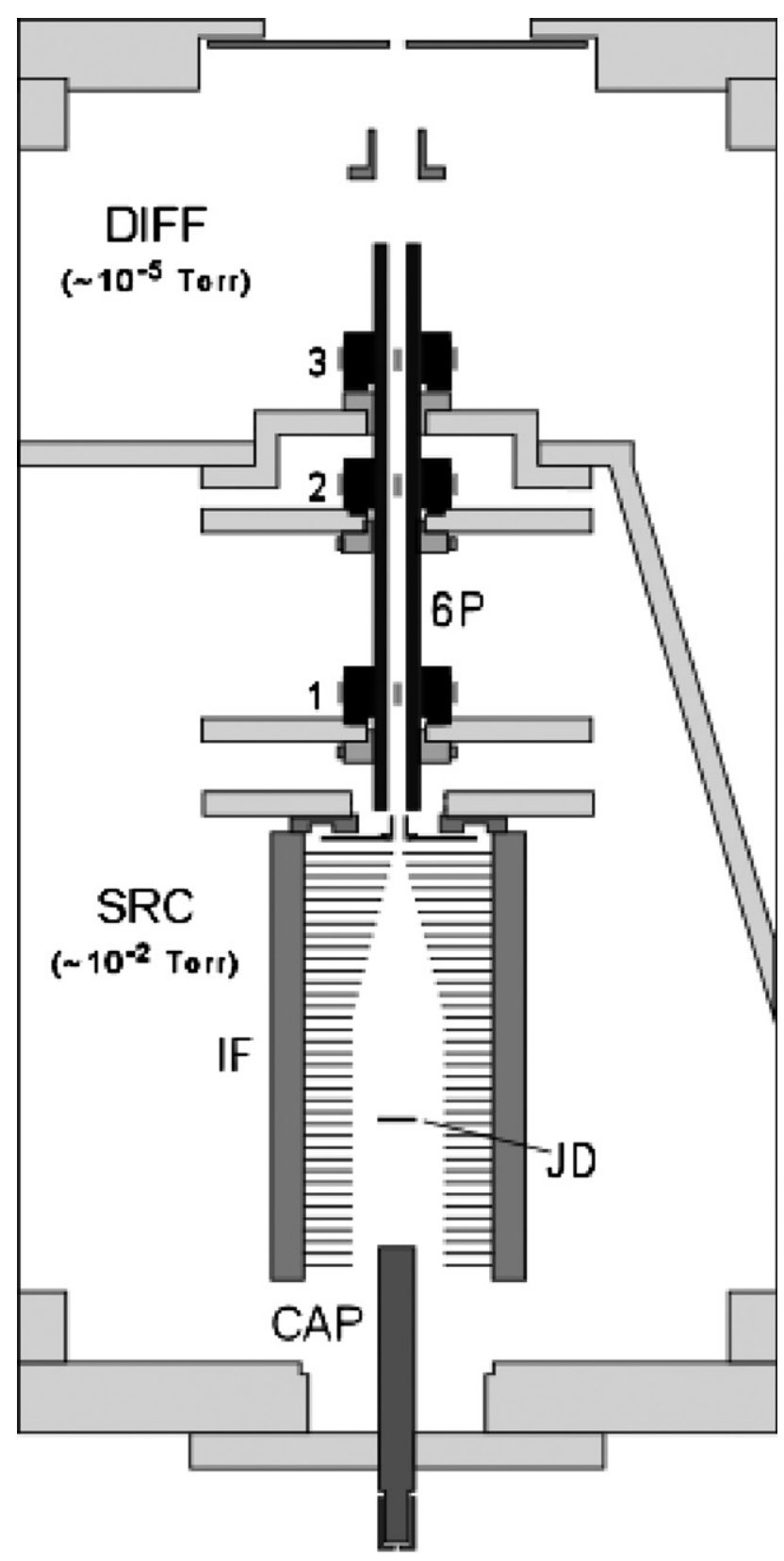

ATM

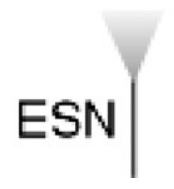

Figure 1. Electrospray ionization-ion funnel-rf hexapole (ESI-IF-6P) source schematic depicting three possible locations of fin electrode assembly. Fin electrodes located at positions 1 and 2 are in the high pressure source (SRC) region. Position 3 of the fin electrodes is in the low pressure differential (DIFF) region. The electrospray needle (ESN) is located in atmosphere (ATM). The heated capillary (CAP) and jet disrupter (JD) are also included for completeness.

single ion counting. The ion intensities as a function of lab frame voltage are converted to absolute cross sections in the center of mass frame as described previously [16]. Additional details of such experiments are 
provided in our previous TCID study of $\mathrm{Ca}^{2+}\left(\mathrm{H}_{2} \mathrm{O}\right)_{x}$ complexes, where $x=5-9$ [15]. There, the methods of analyzing the CID cross sections for single water molecule loss are discussed in detail. These analyses permit quantitative comparison of the threshold energies needed for dissociation.

\section{Results and Discussion}

Fragmentation can occur with either positive or negative voltages applied to the fin electrodes, but the degree of fragmentation is greater for negative voltages. Figure 2 shows the distribution of $\mathrm{Ca}^{2+}\left(\mathrm{H}_{2} \mathrm{O}\right)_{x}$ complexes as a function of the negative $\mathrm{DC}$ fin voltage for a the peak-to-peak rf voltage $\left(\mathrm{V}_{p-p}\right)$ on the hexapole rods of $250 \mathrm{~V}_{p-p}$. At zero volts on the fins, the initial distribution of $x=6-9$ is present with $\mathrm{Ca}^{2+}\left(\mathrm{H}_{2} \mathrm{O}\right)_{7}$ and $\mathrm{Ca}^{2+}\left(\mathrm{H}_{2} \mathrm{O}\right)_{8}$ having the largest intensity and much smaller amounts of $\mathrm{Ca}^{2+}\left(\mathrm{H}_{2} \mathrm{O}\right)_{6}$ and $\mathrm{Ca}^{2+}\left(\mathrm{H}_{2} \mathrm{O}\right)_{9}$. As the fin voltage becomes more negative, the $\mathrm{Ca}^{2+}\left(\mathrm{H}_{2} \mathrm{O}\right)_{9}$, $\mathrm{Ca}^{2+}\left(\mathrm{H}_{2} \mathrm{O}\right)_{8}$, and $\mathrm{Ca}^{2+}\left(\mathrm{H}_{2} \mathrm{O}\right)_{7}$ complexes fragment to produce the $\mathrm{Ca}^{2+}\left(\mathrm{H}_{2} \mathrm{O}\right)_{6}$ species, which reaches a maximum intensity near $-10 \mathrm{~V}$. As the fin voltage is decreased further, $\mathrm{Ca}^{2+}\left(\mathrm{H}_{2} \mathrm{O}\right)_{6}$ begins to fragment giving way to $\mathrm{Ca}^{2+}\left(\mathrm{H}_{2} \mathrm{O}\right)_{5}$, which reaches a maximum intensity near $-15 \mathrm{~V}$. Sequential water loss continues until $\mathrm{Ca}^{2+}\left(\mathrm{H}_{2} \mathrm{O}\right)_{2}$ reaches a maximum intensity at -21 $\mathrm{V}$. Clearly, the dissociation process is not heavily massdependent, as complexes ranging over a factor of about three in mass are effectively dissociated. The fin voltage required to induce a specific amount of fragmentation is coupled to the peak-to-peak voltage $\left(\mathrm{V}_{p-p}\right)$ on the hexapole rods. Compared with the results shown in Figure 2 , the fin voltage required for maximum fragmentation is reduced when there is $200 \mathrm{~V}_{p-p}$ on the hexapole, whereas $300 \mathrm{~V}_{p-p}$ increases the required fin voltage.

The total $\mathrm{Ca}^{2+}\left(\mathrm{H}_{2} \mathrm{O}\right)_{x}(x=2-9)$ ion intensity decreases slowly by about $25 \%$ in going from 0 to $-17.5 \mathrm{~V}$

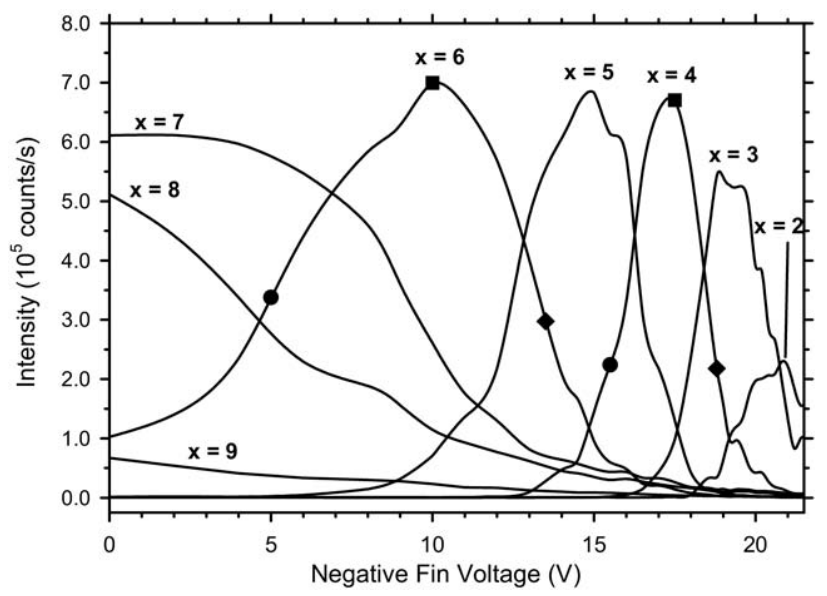

Figure 2. Distribution of $\mathrm{Ca}^{2+}\left(\mathrm{H}_{2} \mathrm{O}\right)_{x}$ complexes as a function of negative fin voltage. The filled symbols on the $\mathrm{Ca}^{2+}\left(\mathrm{H}_{2} \mathrm{O}\right)_{6}$ and $\mathrm{Ca}^{2+}\left(\mathrm{H}_{2} \mathrm{O}\right)_{4}$ intensity profiles correspond to specific fin voltages used to select a specific reactant ion as described further in Figure $3 a$ and $b$. on the fin electrodes. At more negative voltages, the intensity of the hydrated calcium complexes decreases more rapidly, retaining only $25 \%$ of the original intensity at the highest fin voltage examined, $-21.6 \mathrm{~V}$. However, the total ion intensity, which includes a $\mathrm{CaOH}^{+}$fragment, retains $50 \%$ of the original overall ion intensity. The $\mathrm{CaOH}^{+}$ion is the result of a charge separation process forming $\mathrm{CaOH}^{+}$and $\mathrm{H}_{3} \mathrm{O}^{+}$ions from $\mathrm{Ca}^{2+}\left(\mathrm{H}_{2} \mathrm{O}\right)_{2}$, which is lower in energy than simple $\mathrm{H}_{2} \mathrm{O}$ loss $[15,19]$. Thus, the $\mathrm{Ca}^{2+}\left(\mathrm{H}_{2} \mathrm{O}\right)$ complex does not form, which demonstrates that for the $\mathrm{Ca}^{2+}\left(\mathrm{H}_{2} \mathrm{O}\right)_{x}$ systems, $x=2$ represents the critical size structure at which charge separation is a lower energy pathway than water loss.

The $\mathrm{Ca}^{2+}\left(\mathrm{H}_{2} \mathrm{O}\right)_{6}$ complex is the only ion present within the initial distribution that increases in intensity with increasingly negative fin voltages. If this ion is studied by TCID with Xe in the GIBMS, the product cross sections for losing a water molecule from the $\mathrm{Ca}^{2+}\left(\mathrm{H}_{2} \mathrm{O}\right)_{6}$ complex are identical within experimental uncertainty at fin voltages of 0 and $-5 \mathrm{~V}$, Figure 3a. Furthermore, analysis of these two cross sections using the methods previously published [15] yield identical threshold energies. Given that we have previously demonstrated that the ESI-IF-6P source generates thermalized ions at room temperature [14], this result indicates that $\mathrm{Ca}^{2+}\left(\mathrm{H}_{2} \mathrm{O}\right)_{6}$ complexes formed from dissociation of higher solvated complexes, $x=7-9$, are able to undergo sufficient collisions within the source region and emerge from the hexapole thermalized at $300 \mathrm{~K}$ when the dissociating voltage is not too high (on the low voltage side of the distributions shown in Figure 2). However, TCID results for $\mathrm{Ca}^{2+}\left(\mathrm{H}_{2} \mathrm{O}\right)_{6}$ complexes begin to change for more negative fin voltages, Figure $3 a$, clearly indicating a change in the ion population. (It can be noted that the changes in the TCID cross sections observed as a function of fin voltage are reproducible within the overall experimental uncertainties in the cross section magnitudes of $20 \%$ over a time period exceeding two years.) These changes could either be the result of an increase in the ion temperature (leading to lower thresholds for water loss) or to the appearance of alternate isomers that would have lower water binding energies.

The origins of these changes become more obvious when smaller complexes are examined. Figure $3 b$ shows the changes in the TCID cross sections observed as a function of fin voltage for $\mathrm{Ca}^{2+}\left(\mathrm{H}_{2} \mathrm{O}\right)_{4}$ losing a single water molecule. The supporting information, which can be found in the electronic version of this article, shows comparable data for $x=5$. When $\mathrm{Ca}^{2+}\left(\mathrm{H}_{2} \mathrm{O}\right)_{4}$ is generated with $-15.5 \mathrm{~V}$ on the fins (towards the low voltage side of the distribution of Figure 2), the CID cross section shows only a rapid rise from an apparent threshold of $\sim 0.7 \mathrm{eV}$. Increasing the fin voltage to $-17.5 \mathrm{~V}$ produces the largest ion intensity for the $\mathrm{Ca}^{2+}\left(\mathrm{H}_{2} \mathrm{O}\right)_{4}$ mass (Figure 2), however, the $\mathrm{Ca}^{2+}\left(\mathrm{H}_{2} \mathrm{O}\right)_{3}$ product cross section contains a low-energy feature below $\sim 0.8 \mathrm{eV}$ along with a high-energy feature that matches the cross section observed at $-15.5 \mathrm{~V}$. At 


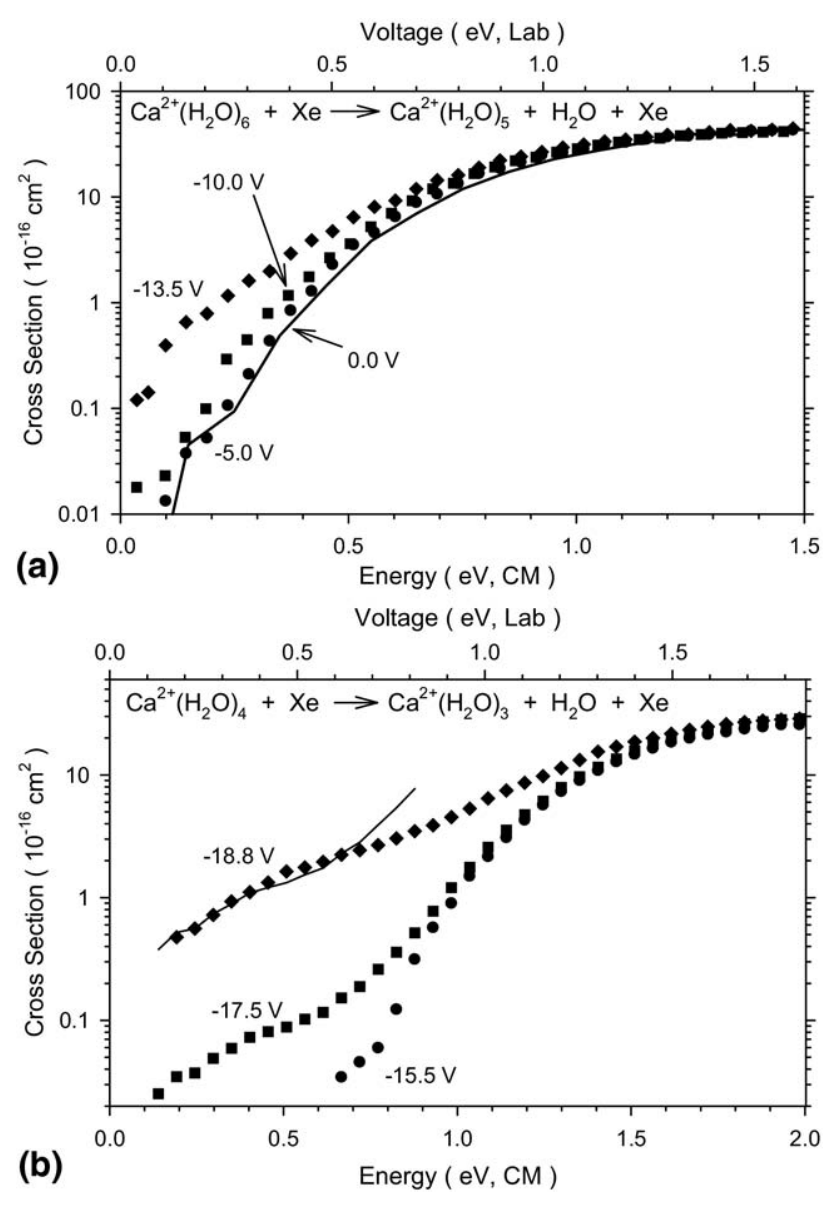

Figure 3. $\mathrm{Ca}^{2+}\left(\mathrm{H}_{2} \mathrm{O}\right)_{x-1}$ product cross sections from the collision-induced dissociation of $\mathrm{Ca}^{2+}\left(\mathrm{H}_{2} \mathrm{O}\right)_{6}$ (part a) and $\mathrm{Ca}^{2+}\left(\mathrm{H}_{2} \mathrm{O}\right)_{4}(\mathbf{b})$ with Xe with fin electrodes in high pressure region (position 2). In (a), the solid line represents the product cross section for losing a single water molecule with a fin voltage of 0.0 V. Filled circles, squares, and diamonds correspond to fin voltages of $-5.0,-10.0$, and $-13.5 \mathrm{~V}$, respectively. In (b), filled circles, squares, and diamonds correspond to fin voltages of $-15.5,-17.5$, and $-18.8 \mathrm{~V}$, respectively. The solid line represents low energy data for $-17.5 \mathrm{~V}$ scaled up by a factor of 15 .

$-18.8 \mathrm{~V}$ on the fins (on the high voltage side of the distribution of Figure 2), the low-energy feature increases in intensity by a factor of 15 while the highenergy feature remains at a similar magnitude. Note that the shape of the low-energy feature (from 0.1 to 0.7 $\mathrm{eV}$ ) does not change as a function of the fin voltage as shown in Figure $3 \mathrm{~b}$. Therefore, we attribute the highenergy feature to dissociation from the ground state structure of the $\mathrm{Ca}^{2+}\left(\mathrm{H}_{2} \mathrm{O}\right)_{4}$ complex in which all four water molecules are bound to the metal ion [15]. The low-energy feature can then be associated with a small percentage of $\mathrm{Ca}^{2+}\left(\mathrm{H}_{2} \mathrm{O}\right)_{3}\left(\mathrm{H}_{2} \mathrm{O}\right)$ in which one water molecule is located in the second solvent shell, and therefore is much more weakly bound. Similar observations are made for the $x=5$ and 6 complexes where a comparison with previously published experimental and theoretical results demonstrates that the highenergy features correspond to ions that are thermal- ized at room temperature and have the ground state structure [15].

The assignment of the low-energy feature to a different isomer arises from several considerations. It is clear, especially for Figure $3 \mathrm{~b}$ and the comparable data for $x=$ 5 , that the low-energy feature cannot be attributed to simply raising the temperature of the parent ions. (This would simply produce a cross section that would broaden to lower energies rather than yielding a distinct low-energy feature.) In addition, we note that for a fin voltage that gives the maximum intensity of a given sized $\mathrm{Ca}^{2+}\left(\mathrm{H}_{2} \mathrm{O}\right)_{x}$ ion, Figure 2, there is an appreciable amount of the $\mathrm{Ca}^{2+}\left(\mathrm{H}_{2} \mathrm{O}\right)_{x-1}$ and $\mathrm{Ca}^{2+}\left(\mathrm{H}_{2} \mathrm{O}\right)_{x+1}$ ions also being produced (about 20\%). Most of the gas load in the source region of the apparatus is the electrospray solvent, here $\mathrm{H}_{2} \mathrm{O}$. Thus, thermalization of the ions occurs by collisions with water, such that the presence of $\mathrm{Ca}^{2+}\left(\mathrm{H}_{2} \mathrm{O}\right)_{x-1}$ ions under these conditions allows rehydration of these complexes to occur. As the rehydration need not form an equilibrium distribution of the $\mathrm{Ca}^{2+}\left(\mathrm{H}_{2} \mathrm{O}\right)_{x}$ complexes, higher energy isomers can be formed. The fact that shapes of the low-energy features in the TCID cross section do not change with fin voltage indicates that these ions are also thermalized. Therefore, the source can be used to form high-energy isomers that are still thermalized. More detailed analysis of such cross sections and comparison with theory is consistent with this hypothesis [20].

\section{Location of Electrodes}

For the purpose of generating thermalized ions for further study by inducing fragmentation, the optimum position of the fins was determined to be located in the high-pressure region of the source (position 2 in Figure 1). Placing the electrodes closer to the entrance of the ion guide (position 1) did not produce as extensive fragmentation. We believe this is because the local pressure in the front of the hexapole is higher such that the ions are not accelerated by the fin voltage appreciably before undergoing a collision and because the ions have significantly more hexapole length to rehydrate and re-equilibrate.

With the fin electrodes located towards the end of the ion guide (position 3 ) in the low-pressure region $\left(\mathrm{P}_{\mathrm{DIFF}} \approx 10^{-5}\right.$ Torr), the amount of fragmentation was extensive, and rehydration was avoided. However, the low-pressure of position 3 means that there is little collisional cooling, such that the ions formed are internally hotter. This is shown in Figure 4 . With $-16.0 \mathrm{~V}$ on the fins in position 3, the $\mathrm{Ca}^{2+}\left(\mathrm{H}_{2} \mathrm{O}\right)_{4}$ ion signal has a maximum intensity. Upon TCID, these ions yield a $\mathrm{Ca}^{2+}\left(\mathrm{H}_{2} \mathrm{O}\right)_{3}$ product cross section that is shifted to lower kinetic energies compared to complexes formed with $-15.5 \mathrm{~V}$ on the fins at position 2 in the highpressure region. A more negative fin voltage further shifts the CID onset. The data for single water molecule loss from $\mathrm{Ca}^{2+}\left(\mathrm{H}_{2} \mathrm{O}\right)_{4}$ ions formed with the fins in position 3 at voltages of -16.0 and $-17.5 \mathrm{~V}$ can be 


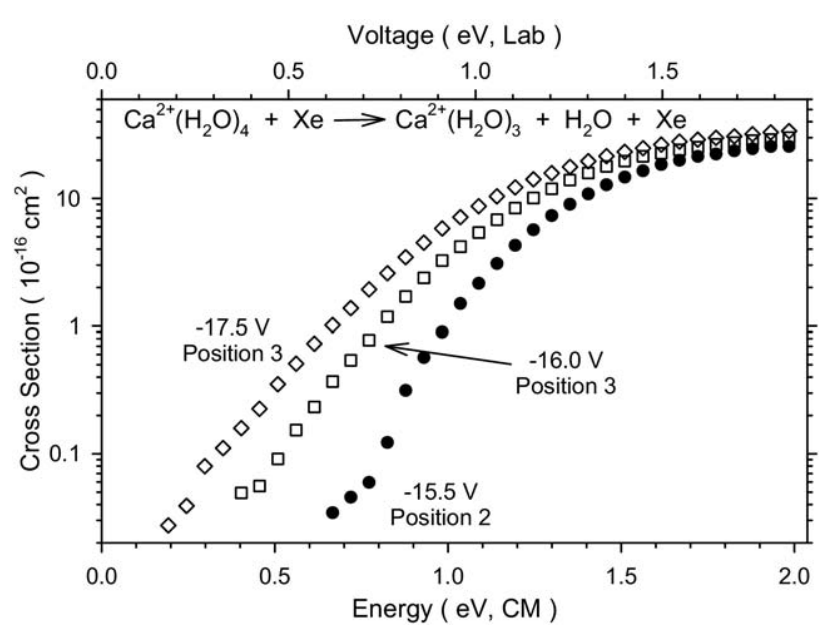

Figure 4. $\mathrm{Ca}^{2+}\left(\mathrm{H}_{2} \mathrm{O}\right)_{3}$ product cross sections from the collisioninduced dissociation of $\mathrm{Ca}^{2+}\left(\mathrm{H}_{2} \mathrm{O}\right)_{4}$ with $\mathrm{Xe}$. Filled circles correspond to a fin voltage of $-15.5 \mathrm{~V}$ and the electrodes at position 2 in the high pressure region $\left(10^{-2}\right.$ Torr). Open squares and diamonds correspond to fin voltages of -16.0 and $-17.5 \mathrm{~V}$, respectively, with fin electrodes in the low pressure region $\left(10^{-5}\right.$ Torr $)$ at position 3.

reproduced (using the same parameters needed to reproduce the thermalized data) if the temperature of the $\mathrm{Ca}^{2+}\left(\mathrm{H}_{2} \mathrm{O}\right)_{4}$ reactant ions is set to 402 and $453 \mathrm{~K}$, respectively. Note that under these conditions, distinctive low-energy features attributable to alternate isomers of the ion beam are absent. This demonstrates that rehydration no longer occurs efficiently. Similar observations are found for the $x=5$ and 6 complexes, as shown in the supporting information.

\section{Conclusions}

An in-source fragmentation technique has been described for implementation within a hexapole ion guide of an electrospray ionization-ion funnel-rf hexapole (ESI-IF-6P) source that is able to produce smaller $\mathrm{Ca}^{2+}\left(\mathrm{H}_{2} \mathrm{O}\right)_{x}$ complexes, where $x=2-5$, from an initial distribution that always consists of complexes where $x=6-9$. When the electrodes are properly placed and modest voltages applied, product cross sections for single water molecule loss from $\mathrm{Ca}^{2+}\left(\mathrm{H}_{2} \mathrm{O}\right)_{x}$ complexes formed in this way indicate that the ions have a single ground state isomer that is thermalized at $300 \mathrm{~K}$. The newly accessed $\mathrm{Ca}^{2+}\left(\mathrm{H}_{2} \mathrm{O}\right)_{x}$ complexes are transmitted to the reaction region as a continuous ion beam and require no intricate pulsing schemes out of the hexapole ion guide. Other in-source fragmentation techniques that take place in ion guides external to FTICR mass spectrometers inherently require the ions to be stored in the external linear ion trap, fragmented, and pulsed into the ICR cell for detection [6,7], whereas others are amenable to continuous operation $[8,13]$. The present technique could prove useful for systems operating in continuous transmission mode, such as a source region multipole ion guide before the first quadrupole within a triple quadrupole apparatus. A significant advantage of the fin electrodes is their implementation into an ion guide, which is relatively straightforward with respect to other methods and can be done at modest machining and electrical costs. The versatility of the present method can be illustrated by the fact that we have used this in-source fragmentation technique to generate $\mathrm{M}^{2+}\left(\mathrm{H}_{2} \mathrm{O}\right)_{x}$ complexes, where $\mathrm{M}=\mathrm{Mg}, \mathrm{Ca}, \mathrm{Sr}, \mathrm{Ba}$, and $\mathrm{Cd}$ with $x$ values lying between the critical size (where charge separation channels prevent formation of smaller hydrated complexes) and the complexes making up the initial distribution of the $\mathrm{M}^{2+}\left(\mathrm{H}_{2} \mathrm{O}\right)_{x}$ system, as well as $\mathrm{Li}^{+}$(amino acid) complexes, which are otherwise formed in low abundance in our ESI source because these complexes are easily solvated.

\section{Acknowledgments}

The authors acknowledge funding for this work provided by the National Science Foundation under grant no. 0748790.

\section{Appendix A Supplementary Material}

Supplementary material associated with this article may be found in the online version at doi:10.1016/ j.jasms.2009.08.024.

\section{References}

1. Loo, J. A.; Edmonds, C. G.; Smith, R. D. Primary Sequence Information from Intact Proteins by Electrospray Ionization Tandem Mass Spectrometry. Science 1990, 248, 201-204.

2. Loo, J. A.; Edmonds, C. G.; Smith, R. D. Tandem Mass Spectrometry of Very Large Molecules: Serum Albumin Sequence Information from Multiply Charged Ions Formed by Electrospray Ionization. Anal. Chem. 1991, 63, 2488-2499.

3. Zhai, H.; Han, X.; Breuker, K.; McLafferty, F. W. Consecutive Ion Activation for Top Down Mass Spectrometry: Improved Protein Sequencing by Nozzle-Skimmer Dissociation. Anal. Chem. 2005, 77, 5777quen

4. Gauthier, J. W.; Trautman, T. R.; Jacobson, D. B. Sustained OffResonance Irradiation for Collision-Activated Dissociation Involving Fourier Transform Mass Spectrometry. Collision-Activated Dissociation Technique That Emulates Infrared Multiphoton Dissociation. Anal. Chim. Acta 1991, 246, 211-225.

5. Little, D. P.; Speir, J. P.; Senko, M. W.; O'Connor, P. B.; McLafferty, F. W. Infrared Multiphoton Dissociation of Large Multiply-Charged Ions for Biomolecule Sequencing. Anal. Chem. 1994, 66, 2809-2815.

6. Sannes-Lowery, K.; Griffey, R. H.; Kruppa, G. H.; Speir, J. P.; Hofstadler S. Multipole Storage Assisted Dissociation, a Novel In-Source Dissociation Technique for Electrospray Ionization Generated Ions. Rapid Commun. Mass Spectrom. 1998, 12, 1957-1961.

7. McFarland, M. A.; Hendrickson, C. L.; Marshall, A. G. Ion "Threshing": Collisionally Activated Dissociation in an External Octopole Ion Trap by Oscillation of an Axial Electric Potential Gradient. Anal. Chem. 2004, $76,1545-1549$.

8. Hofstadler, S. A.; Sannes-Lowery, K. A.; Griffey, R. H. Infrared Multiphoton Dissociation in an External Ion Reservoir. Anal. Chem. 1999, 71, 2067-2070.

9. Pan, C.; Hettich, R. L. Multipole-Storage-Assisted Dissociation for the Characterization of Large Proteins and Simple Protein Mixtures by ESI-FTICR-MS. Anal. Chem. 2005, 77, 3072-3082.

10. Collings, B. A.; Stott, W. R.; Londry, F. A. Resonant Excitation in a Low-Pressure Linear Ion Trap. J. Am. Soc. Mass Spectrom. 2003, 14 622-634.

11. Campbell, J. M.; Collings, B. A.; Douglas, D. J. A New Linear Ion Trap Time-of-Flight System with Tandem Mass Spectrometry Capabilities. Rapid Commun. Mass Spectrom. 1998, 12, 1463-1474.

12. Collings, B. A. Increased Fragmentation Efficiency of Ions in a Low Pressure Linear Ion Trap with an Added dc Octopole Field. J. Am. Soc. Mass Spectrom. 2005, 16, 1342-1352.

13. Vilkov, A. N.; Bogdanov, B.; Paša-Tolić, L.; Prior, D. C.; Anderson, G. A.; Masselson, C. D.; Moore, R. J.; Smith, R. D. Tailored noise waveform/ 
collision-induced dissociation of ions stored in a linear ion trap combined with liquid chromatography/Fourier transform ion cyclotron resonance mass spectrometry. Rapid Commun. Mass Spectrom. 2004, 18, 2682-2690.

14. Moision, R. M.; Armentrout, P. B. An Electrospray Ionization Source for Thermochemical Investigation with the Guided Ion Beam Mass Spectrometer. J. Am. Soc. Mass Spectrom. 2007, 18, 1124-1134.

15. Carl, D. R.; Moision, R. M.; Armentrout, P. B. Binding Energies for the Inner Hydration Shells of $\mathrm{Ca}^{2+}$ : An Experimental and Theoretical Investigation of $\mathrm{Ca}^{2+}\left(\mathrm{H}_{2} \mathrm{O}\right)_{x}$ complexes $(x=5-9)$. Int. J. Mass Spectrom. 2007, 265, 308-325.

16. Ervin, K. M.; Armentrout, P. B. Translational Energy Dependence of $\mathrm{Ar}^{+}+\mathrm{XY} \rightarrow \mathrm{ArX}^{+}+\mathrm{Y}\left(\mathrm{XY}=\mathrm{H}_{2}, \mathrm{D}_{2}, \mathrm{HD}\right)$ from thermal to $30 \mathrm{eV} \mathrm{cm}$. J. Chem. Phys. 1985, 83, 166-189.
17. Muntean, F.; Armentrout, P. B. Guided Ion Beam Study of CollisionInduced Dissociation Dynamics: Integral and Differential Cross Sections. J. Chem. Phys. 2001, 115, 1213-1228.

18. Teloy, E.; Gerlich, D. Integral Cross Sections for Ion-Molecule Reactions. 1. The Guided Beam Technique. Chem. Phys. 1974, 4, 417-427.

19. Beyer, M.; Williams, E. R.; Bondybey, V. E. Unimolecular Reactions of Dihydrated Alkaline Earth Metal Dications $\mathrm{M}^{2+}\left(\mathrm{H}_{2} \mathrm{O}\right)_{2}, \mathrm{M}=\mathrm{Be}, \mathrm{Mg}$ $\mathrm{Ca}, \mathrm{Sr}$, and Ba: Salt-Bridge Mechanism in the Proton-Transfer Reaction $\mathrm{M}^{2+}\left(\mathrm{H}_{2} \mathrm{O}\right)_{2} \rightarrow \mathrm{MOH}^{+}+\mathrm{H}_{3} \mathrm{O}^{+}$. J. Am. Chem. Soc. 1999, 121, 1565-1573.

20. Carl, D. R.; Armentrout, P. B. Experimental Investigation of the Inner Shell Hydration Energies of $\mathrm{Ca}^{2+}$ : Threshold Collision-Induced Dissociation of $\mathrm{Ca}^{2+}\left(\mathrm{H}_{2} \mathrm{O}\right)_{x}$ complexes $(x=2-8)$. J. Phys. Chem. A, unpublished (manuscript in preparation). 